\title{
Violence at work and its relationship with burnout, depression and anxiety in healthcare professionals of the emergency services
}

\author{
Gloria M. Roldán ${ }^{1}$, Isabel C. Salazar ${ }^{2 *}$, Laura Garrido ${ }^{1}$, Juan M. Ramos ${ }^{3}$ \\ 1“Virgen de las Nieves” University Hospital, Granada, Spain \\ ${ }^{2}$ University of Granada, Granada, Spain; *Corresponding Author: salazar_isabel@hotmail.com \\ 3،La Caleta” Healthcare Center, Granada, Spain
}

Received 20 November 2012; revised 21 December 2012; accepted 29 December 2012

\begin{abstract}
The aim of this study was to examine the possible relationship between physical and psychological aggression suffered in the workplace and professional burnout, depression and anxiety suffered by healthcare professionals of the emergency services. Methods: 315 physicians, nurses, orderlies and ambulance drivers of Critical Care and Emergency Devices (CCED) in the Andalusian Public Health System, in the province of Granada (Spain) participated. They were interviewed about the exposure to violence at work and answered a battery of questions that measured burnout, depression and anxiety. Results: Physical aggression was significantly related to emotional exhaustion, personal accomplishment at work, depression and anxiety. Psychological aggression was associated with personal accomplishment. Logistic regression showed that the CCED professionals who have suffered physical aggression were 4.2 and 2.6 times more likely to have suffered anxiety and reduced personal accomplishment, respectively, than those who did not suffer physical aggression. On the other hand, feelings of anxiety and reduced personal accomplishment increase the professionals' risk (3.4 and 2.1 times more likely, respectively) of suffering from physical aggression. Conclusion: The results suggest that exposure to violence is related to the other psychological problems tested: emotional exhaustion and personal accomplishment (two components of burnout), depression and anxiety. In addition, physical violence is a risk factor for anxiety and diminished personal accomplishment of the CCED professionals.
\end{abstract}

Keywords: Workplace Violence; Aggression;
Burnout; Depression; Anxiety; Health Professionals; Emergency Services

\section{INTRODUCTION}

Workplace violence is universal in the health sector, although local characteristics may vary. Workplace violence is any situation in which the person is the subject of abuse, threats or attacks in circumstances related to their work (or professional activity), having their safety, well-being or health threatened explicitly or implicitly $[1,2]$. There are two types of workplace violence: physical violence, which refers to the use of physical force against another person or group that results in physical, sexual or psychological harm. This includes beating, kicking, slapping, stabbing, shooting, pushing, biting, pinching, etc. On the other hand, psychological violence, which refers to the intentional use of power, includes threat of physical force against another person or group that can result in harm to physical, mental, spiritual, moral or social development. This includes verbal abuse, uncivil behavior, lack of respect, disparaging attitude, intimidation, mobbing, harassment, and threats [1].

A research carried out by a joint program on workplace violence in the health sector shows that more than half of the health sector personnel surveyed had experienced at least one incident of physical or psychological violence in the year previous to the study. In South Africa that figure reached $61 \%$, in Thailand 54\%, in Portugal $60 \%$. In Bulgaria $37 \%$ and Lebanon $41 \%$ of the respondents reported incidents of verbal violence which is a form of psychological abuse [1]. This study showed than ambulance staff exposure to violence is extremely high in all countries investigated. In all the studies, nurses and physicians also report very high levels of exposure to violence. Alameddine et al. showed that in Beirut (Lebanon) over the past 12 months, four out of five emergency department employees were verbally 
abused and one in four was physically assaulted [3]. More recently, a study in 10 European countries showed that nurses in France (39\%), UK (29\%) and Germany (28\%) reported the highest rates of violence [4].

In recent years, violence against healthcare professionals seems to have increased in Spain and numbers are as high as seen in the aforementioned countries. In Barcelona (Catalonia), one third of interviewed physicians had suffered a violent episode throughout their professional career (verbal aggression 44\%, physical aggression $28 \%$, threats $26 \%$ ), predominantly in the emergency services (45\%) [5]. In Jaen (Andalusia), out of 68 physicians of primary care, $58 \%$ had suffered aggression (verbal abuse $85 \%$, threats $67.5 \%$, and physical aggression 12.5\%) [6]. Between January 2007 and December 2009, 1940 violent incidents were reported in 60 healthcare centers in Catalonia. Physical violence was reported in one third of these incidents and verbal violence in more than half of them [7].

In Aragon and Castilla-La Mancha, out of 1845 medical professionals evaluated, $64 \%$ had been a victim of psychological violence (threats, coercion or insults) and $11 \%$ had suffered physical aggression. The percentage of insults received was higher for physicians (61.6\%) and the threats were primarily aimed at managers (65\%) and secondarily at physicians (60.9\%). Again, the emergency services were the most affected (87\%). The percentage of physical aggression was higher for physicians (19.4\%), followed by orderlies (18.2\%) and nurses (17\%) [8].

In Castilla and Leon, medical professionals (especially physicians) and nursing staff were the most affected by violence directed at them personally followed by attendants and orderlies, although the percentage of affected individuals in each category is not reported. The majority of aggression was verbal (65\%) [9].

In Granada (Andalusia), Roldán et al. found high percentages of professionals in emergency services who had suffered from some sort of aggression during their working years (physicians 98.9\%, nurses 95.3\%, orderlies and ambulance drivers 91.8\%). Psychological aggression was distributed similarly (99\% physicians, $94.1 \%$ nurses, and 89.7\% for orderlies and ambulance drivers). However, there was variation in respect to physical aggression, the nurses $(27.1 \%)$ being the ones who were most affected, followed by the physicians (26.3\%) and finally the orderlies and ambulance drivers (13.4\%) [10].

Violence at work can trigger a range of physical and psychological outcomes in victims. Most victims of workplace violence report being affected emotionally by the experience. Emotional experiences to physical and emotional violence can include anger, frustration, shock, annoyance, fear, anxiety, stress depression, and sleep disruption [11]. In the work environment, exposure to violence has recently been linked to other psychological problems such as burnout. Maslach and Jackson defined burnout as a syndrome characterized by emotional exhaustion (being emotionally overextended and exhausted by one's work), depersonalization (having an unfeeling and impersonal response toward recipients of one's services), and diminished personal accomplishment (having diminished feelings of competence and successful achievement in one's work with people) [12]. Some studies have shown that exposure to violence is associated with burnout. For example, Moreno et al. report that family physicians who had suffered violence were 2.9 times more at risk of burnout than those who had not been assaulted [6], and in later years, Estryn-Behar et al. also found a risk number very similar although slightly lower $(\mathrm{OR}=2.4)$ in a cohort of nurses [4]. Specifically, it has been found that physical violence is associated with burnout [8] and that psychological violence is associated with serious outcomes including significantly higher levels of anxiety [8] and burnout $[3,8]$.

Just as violence can have negative psychological consequences, it has also been found that burnout can increase the risk of exposure to violence in the workplace. Alameddine et al. found that respondents reporting a high level of emotional exhaustion had more than 2.1 times higher odds of exposure to a higher level of verbal abuse compared to respondents with an average level of emotional exhaustion. Similarly, respondents with a low level of personal accomplishment had 2.7 times higher odds of being exposed to higher levels of verbal abuse compared to their counterparts with average levels of personal accomplishment. Finally, the employees with a high and average level of depersonalization had 3.40 and 3.74 times higher odds of being exposed to higher levels of verbal abuse compared to employees with low levels of depersonalization [3].

All of the aforementioned is very significance because there is empirical support for some psychological problems (e.g., depression, anxiety, etc.) associated with exposure to violence at work also being predictors of burnout $[13,14]$.

Taking into consideration that emergency departments are identified as a place where workers are disproportionally exposed to violence compared to their counterparts in other departments $[1,4,7,11]$, the aim of this study is to examine the relationship between physical and psychological aggression in the workplace and anxiety, depression and burnout, as suffered by healthcare professionals in the Critical Care and Emergency Devices of the Andalusian Health Service (Spain).

\section{METHODS}

\subsection{Participants}

315 sanitary professionals in the Critical Care and 
Emergency Devices (CCED) of the Andalusian Health Service in the province of Granada (Spain) were interviewed. Table 1 provides socio-demographic and occupational data of participants.

\subsection{Instruments}

The CCED professionals were interviewed. Each interview took 55 minutes (approximately) and there was a psychologist in charge who traveled to the workplaces of the participants. In some cases, the length of the interview went over the allotted time and prevented dedication of more time to finalize it, and that is why the sample considered for each different statistical analysis varies.

For the data collection the following was used: 1) an ad hoc interview which gathers socio-demographic and occupational data as well as data related to exposure to violent events in the workplace. The interview allows for identification of participants who have been assaulted, the source of the assault, the type of assault, the number of assaults suffered during the years worked, if they have been off work, the treatment received, the areas affected as a consequence of the assaults, if they know of the Prevention Plan and Assault Assistance for Andalusian Health Service Professionals and their perception on institutional support. 2) The Maslach Burnout Inventory (MBI), a 22-item questionnaire that measures burnout syndrome across three subscales: Emotional exhaustion, Depersonalization, and Personal accomplishment. The Emotional exhaustion subscale measures workers' feelings of emotional wear-out and fatigue at work. The Depersonalization subscale measures workers' degree of being impersonal and distant in delivering care, treatment and instructions to recipients of services. Furthermore, the Personal accomplishment subscale measures an employee's level of competence and feeling of pro-

Table 1. Socio-demographic and professional characteristics of participants.

\begin{tabular}{llccccc}
\hline \multicolumn{1}{c}{ Variables } & $\mathrm{n}$ & $\%$ & & & \\
\hline \multirow{2}{*}{ Gender } & Male & 196 & 62.6 & & & \\
& Female & 117 & 37.4 & & & \\
Living with & Yes & 243 & $77.4 \%$ & & & \\
partner & No & 71 & $22.6 \%$ & & & \\
\multirow{2}{*}{$\begin{array}{l}\text { Professional } \\
\text { category }\end{array}$} & Nhysician & 111 & 35.2 & & & \\
& Ord. \& amb. & 110 & 34.9 & & & \\
& & 94 & 29.8 & & & \\
Age & (years) & 312 & 43.92 & 9.05 & 22 & 63 \\
Years worked & & 311 & 14.30 & 7.46 & 1 & 35 \\
\hline
\end{tabular}

${ }^{\mathrm{a}}$ Ord. \& amb. = Orderlies \& ambulance drivers. fessional achievement at work. Each of the questions in the MBI is scored on a 7-point Likert scale (from $0=$ "never" to 6 = “daily”). The internal consistency (Cronbach's alpha) of the MBI was of 0.68, 0.81 for the Emotional exhaustion subscale, 0.68 for the Depersonalization subscale, and 0.71 for the Personal accomplishment subscale. 3) The Beck Depression Inventory (BDI), a 21-item inventory that measures the magnitude of the depression. Each of the questions has four alternative answers (ranging from 0 - 3 points) that are listed according to the severity. The total score allows recognition of whether the subject presents clinical symptoms of depression. The alpha of the BDI was 0.87. 4) The Beck Anxiety Inventory (BAI), a 21-item inventory that measures the severity of physical symptoms related to anxiety experienced throughout the past week. It uses a 4point Likert scale (from $0=$ "not at all" to $3=$ "severely"). The total score allows recognition of whether the subject presents clinical anxiety symptoms. The alpha of the BAI was of 0.93 .

\subsection{Statistical Analysis}

Data was entered in the Statistical Package for the Social Sciences (SPSS), version 13.0. Exposure to physical aggression and psychological aggression were considered two separate variables and were analyzed separately in order to better understand the factors associated with each. The anxiety and depression (that were originally measured on a 4-point scale) were regrouped into two categories. Chi-square $\left(\chi^{2}\right)$ or Fischer $(F)$ tests were used. Subsequently, logistic regression was used to test whether physical and psychological aggression in the workplace acted as a risk factor for the rest of the psychological variables evaluated, and vice versa.

\subsection{Ethical Considerations}

Participation in the study was voluntary. Informed verbal consent to the interview was obtained from all respondents, who were free to withdraw at any time or to refuse to answer any of the questions. Respondents were not compensated financially. This study was approved by the Ethics Committee of "Virgen de las Nieves" Hospital's clinical research department and it does not break the agreements of the Helsinki Declaration.

\section{RESULTS}

\subsection{Co-Relational Analysis}

Correlations between physical and psychological aggression and other psychological variables assessed (anxiety, depression and 3-components of burnout: emotional exhaustion, depersonalization and personal accomplishment) were analyzed. Chi-square or Fischer tests 
were used for this analysis. It was found that exposure to physical aggression was associated with anxiety ( $p=$ $0.000)$, personal accomplishment $(p=0.006)$, emotional exhaustion $(p=0.025)$, and depression $(p=0.19)$. On the other hand, exposure to a psychological aggression was associated with personal accomplishment $(p=0.044)$

(Table 2).

\subsection{Multivariate Analysis}

Psychological consequences of exposure to physical and psychological violence. A binary logistic regression analysis was conducted to study the significant associations with exposure to physical or psychological aggression among the CCED professionals. This analysis was based on the fact that physical aggression and psychological aggression are dichotomous variables.

Results showed that healthcare professionals who were physically assaulted had 4.24 times (95\% CI: 1.96, 9.16; $p$-value: 0.000 ) greater odds of suffering anxiety and 2.58 times (95\% CI: 1.35, 4.93; $p$-value: 0.004) greater odds of not feeling personal accomplishment in their work than those professionals who had not been physically assaulted.

Psychological variables of risk from physical and psychological violence. A multivariate logistic regression model was built taking physical aggression as a dependent variable and as independent variables those that were statistically significant in the bivariate analysis (emotional exhaustion, personal accomplishment, anxiety and depression).

The results showed that healthcare professionals with anxiety and reduced personal accomplishment had higher risk of physical aggression. Specifically, CCED professionals with anxiety had 3.4 times (95\% CI: 1.53, 7.58; $p$-value: 0.003 ) greater odds of being exposed to physical aggression compared to their colleagues without anxiety. Similarly, respondents with reduced personal accomplishment had 2.06 times (95\% CI: 1.03, 4.10; $p$-value:

Table 2. Distribution of the subjects between emotional exhaustion, personal accomplishment, depression and anxiety according to the type of aggression.

\begin{tabular}{|c|c|c|c|c|c|c|c|c|}
\hline \multicolumn{3}{|c|}{ Variables } & \multicolumn{3}{|c|}{ Physical aggression } & \multicolumn{3}{|c|}{ Psychological aggression } \\
\hline & & & Yes & No & Total & Yes & No & Total \\
\hline \multirow{6}{*}{ Emotional exhaustion } & \multirow{2}{*}{ No } & $\mathrm{N}$ & 36 & 151 & 187 & 174 & 13 & 187 \\
\hline & & $\%$ & 19.3 & 80.7 & 100.0 & 93.0 & 7.0 & 100.0 \\
\hline & \multirow{2}{*}{ Yes } & $\mathrm{N}$ & 22 & 43 & 65 & 64 & 1 & 65 \\
\hline & & $\%$ & 33.8 & 66.2 & 100.0 & 98.5 & 1.5 & 100.0 \\
\hline & \multirow{2}{*}{ Total } & $\mathrm{N}$ & 58 & 194 & 252 & 238 & 14 & 252 \\
\hline & & $\%$ & 23.0 & 77.0 & 100.0 & 94.4 & 5.6 & 100.0 \\
\hline \multirow{6}{*}{ Personal accomplishment } & \multirow{2}{*}{ No } & $\mathrm{N}$ & 21 & 35 & 56 & 56 & 0 & 56 \\
\hline & & $\%$ & 37.5 & 62.5 & 100.0 & 100.0 & 0.0 & 100.0 \\
\hline & \multirow{2}{*}{ Yes } & $\mathrm{N}$ & 37 & 159 & 196 & 182 & 14 & 196 \\
\hline & & $\%$ & 18.9 & 81.1 & 100.0 & 92.9 & 7.1 & 100.0 \\
\hline & \multirow{2}{*}{ Total } & $\mathrm{N}$ & 58 & 194 & 252 & 238 & 14 & 252 \\
\hline & & $\%$ & 23.0 & 77.0 & 100.0 & 94.4 & 5.6 & 100.0 \\
\hline \multirow{6}{*}{ Depression } & \multirow{2}{*}{ No } & $\mathrm{N}$ & 44 & 172 & 216 & 203 & 13 & 216 \\
\hline & & $\%$ & 20.4 & 79.6 & 100.0 & 94.0 & 6.0 & 100.0 \\
\hline & \multirow{2}{*}{ Yes } & $\mathrm{N}$ & 14 & 21 & 35 & 35 & 0 & 35 \\
\hline & & $\%$ & 40.0 & 60.0 & 100.0 & 100.0 & 0.0 & 100.0 \\
\hline & \multirow{2}{*}{ Total } & $\mathrm{N}$ & 58 & 193 & 251 & 238 & 13 & 251 \\
\hline & & $\%$ & 23.1 & 76.9 & 100.0 & 94.8 & 5.2 & 100.0 \\
\hline \multirow{6}{*}{ Anxiety } & \multirow{2}{*}{ No } & $\mathrm{N}$ & 42 & 178 & 220 & 206 & 14 & 220 \\
\hline & & $\%$ & 19.1 & 80.9 & 100.0 & 93.6 & 6.4 & 100.0 \\
\hline & \multirow{2}{*}{ Yes } & $\mathrm{N}$ & 16 & 16 & 32 & 32 & 0 & 32 \\
\hline & & $\%$ & 50.0 & 50.0 & 100.0 & 100.0 & 0.0 & 100.0 \\
\hline & \multirow{2}{*}{ Total } & $\mathrm{N}$ & 58 & 194 & 252 & 238 & 14 & 252 \\
\hline & & $\%$ & 23.0 & 77.0 & 100.0 & 94.4 & 5.6 & 100.0 \\
\hline
\end{tabular}


0.040) greater odds of being exposed to physical aggression compared to their colleagues with higher personal accomplishment.

\section{DISCUSSION}

This study allowed evaluation of the relationships between physical and psychological aggression suffered in the workplace and professional burnout, depression and anxiety suffered by healthcare professionals of the emergency services, in the province of Granada (Spain).

Study results showed that the exposure to violence is associated with burnout, anxiety and depression in CCED professionals. However, once each type of violence (physical/psychological) is analyzed separately, some differences in relation to the other psychological variables were found. Physical aggression showed a significant link with anxiety, depression, emotional exhaustion and low personal accomplishment (aspects of burnout), whereas psychological aggression was associated solely with low personal accomplishment.

According to Estryn-Behar et al., a high and medium frequency of violence is associated with higher levels of burnout; also, violence appears to be an important risk factor for burnout as it increases the risk 1.4 and 1.9 times in those who have been assaulted monthly and weekly respectively, compared to those who have not been assaulted [4]. The relationship between the different types of assault suffered by professionals and the presence of burnout is not explained. This could be an important question due to the fact that different types of aggression happen at different frequencies and can have a different impact on people.

According to the present investigation, physical aggression suffered by healthcare professionals throughout their working years increases the risk of suffering anxiety and reduced personal accomplishment, in comparison to those who have not experienced any physical aggression; whereas exposure to psychological aggression does not lead to any significant risk for professionals in this sense. These results partially contradict what Alameddine et al. suggest, given that in their study verbal abuse was significantly associated with the three subscales of burnout (Emotional exhaustion, Depersonalization and Personal accomplishment) in the Beirut emergency departments [3]. A possible explanation for the results of the present study is that patients and those accompanying them (who tend to be those exert more actions of this kind against CCED professionals) $[10,11]$ tend to psychologically assault professionals, alluding to a lack of competence or professional efficiency at the time they are taken into care. The insults, humiliations and even threats come from people who, at the time (in the emergency services department) see their situation as difficult, sometimes critical, and which overcomes their coping skills. It is clear that even though it does not justify the verbal abuse, it is understandable that in said circumstances some people (due to a coping skills deficit) express their discomfort through these kinds of aggressive responses and that professionals consider this reaction from patients as something to expect from their job, the reason for which is, in some way, a method of "protecting themselves" from suffering reduced personal accomplishment and, in general, from suffering burnout.

Another question that was analyzed in this investigation was the psychological impact of different types of violence against professionals. In agreement with the data obtained, the consequences derived from exposure to physical violence are different from the data obtained for psychological violence. Physical aggression, unlike psychological aggression, increases the probability of suffering anxiety and reduced personal accomplishment, the reason for this is thought to be that physical aggression has a higher psychological impact in healthcare professionals than psychological aggression. The presence of anxiety problems in the cases of physical aggression is clearly justified by the nature of the stimulus (a strike, a push, an injury, etc.), because this is in itself harmful and automatically triggers an emotional reaction of fear. This kind of response implies an increased physiological activation which, if not handled adequately, can lead to the person subsequently developing problems with anxiety. In short, a physical stimulus is potentially stronger and more harmful than a psychological (or verbal) stimulus and therefore, it is expected that physical aggression increases the risk of suffering from anxiety, as well as low personal accomplishment, in comparison to psychological aggression. As has been previously described, psychological aggression, despite being aimed at attacking the self-efficiency and professional competence, does not have as high an impact as to affect an individual's personal accomplishment in the workplace.

Until recently, this relationship has been analyzed in only one sense: the psychological effects of violence. Many studies indicate that violence is a risk factor for burnout and can entail emotional experiences such as anxiety, depression, sleep problems, etc. However, there are also studies that indicate the opposite. With regards to this, the present investigation was able to determine that the presence of a high level of anxiety and reduced personal accomplishment increased the probability of suffering physical aggression, compared to those subjects who did not have the aforementioned psychological problems.

This risk model indicates that those people who suffer from anxiety and reduced personal accomplishment have a greater chance of being physically assaulted. Said model could be better understood if anxiety was consid- 
ered to be an emotional reaction to disproportionate fear or worry (apprehensive expectation) in light of situations in which healthcare professionals feel themselves incapable of managing. If this preoccupation and physiological-emotional activation is significant, it is highly probable that behavior is negatively affected and at the moment of interacting with the patients they manifest their nervousness and will not use (or will not have) the sufficient and appropriate repertoire of skills to manage difficult situations that can arise in an emergency services department.

Unlike what has been said up until now, there are some studies with nursing staff that revealed no associations between reported violence and burnout $[15,16]$. The contradiction between these cases could be due to the complexity of the phenomenon. The idea of "zero tolerance" towards violence is promoted socially, but it is feasible that some healthcare professionals consider that violence coming from patients is "expected" and that "it is part of the job" $[15,16]$. It is an attitude which could moderate the appearance of burnout, but further investigation is required.

\section{CONCLUSION}

Physical violence is linked to anxiety and burnout. Physical aggression is a risk factor for anxiety and low personal accomplishment at work. Nevertheless, the opposite also occurs. That is to say, subjects with anxiety and low personal accomplishment have a greater risk of suffering physical aggression. This is possibly the first investigation performed in Spain that provides information on exposure to violence and the risk of finding important psychological problems linked to it (such as burnout and anxiety). However, more investigation will be necessary in order to clarify the causal relationship between these phenomena.

\section{ACKNOWLEDGEMENTS}

We thank the healthcare professionals of the Andalusian Public Health System in the province of Granada, who agreed to be part of the cohort in this study. This work has been possible thanks to the funding from the Andalusian Public Fund for Bio-Sanitary Investigation of Oriental Andalusia-Alejandro Otero (FIBAO B15/2006), the Carlos III Health Institute and European Regional Development Fund (ERDF) (FIS 07/0440).

\section{REFERENCES}

[1] World Health Organization (2012) New research shows workplace violence threatens health services.

http://www.who.int/mediacentre/news/releases/release37/ en/index.html

[2] International Labour Organisation (2003) Code of practice on workplace violence in services sectors and meas- ures to combat this phenomenon.

http://www.ilo.org/safework/info/standards-and-instrume nts/codes/WCMS_107705/lang--en/index.htm

[3] Alameddine, M., Kazzi, A., El-Jardali, F., Dimassi, H. and Maalouf, S. (2011) Occupational violence at Lebanese emergency departments: Prevalence, characteristics and associated factors. Journal of Occupational Health, 53, 455-464. doi:10.1539/joh.11-0102-OA

[4] Estryn-Behar, M., van der Heijden, B., Camerino, D., Fry, C., Le Nezet, O., Conway, P.M., Hasselhorn, H.M. and NEXT Study Group (2008) Violence risks in nursing -Results from the European NEXT Study. Occupational Medicine, 58, 107-117. doi:10.1093/occmed/kqm142

[5] Colegio Oficial de Médicos de Barcelona (2004) Guide to preventing and managing violence against physicians in the workplace [Guía para prevenir y gestionar la violencia en el lugar de trabajo contra los médicos]. Cuadernos de la Buena Praxis, 17, 6.

http://issuu.com/comb/docs/praxi17?mode=embed\&layou t=http\%3A//skin.issuu.com/v/light/layout.xml\&showFlip Btn=true

[6] Moreno Jiménez, M.A., Vico Ramírez, F., Zerolo Andrey, F.J., López Rodríguez, A., Herrera Serena, P. and Mateios Salidoc, M.J. (2005) Analysis of patients' violence in primary care [Análisis de la violencia del paciente en atención primaria]. Atención Primaria, 36, 152-158. doi:10.1157/13077484

[7] Cervantes, G., Blanch, J.M. and Hermoso, D. (2010) Workplace violence against healthcare professionals in Catalonia notified online (2007-2009) [Violencia ocupacional contra profesionales sanitarios en Cataluña notificada por Internet (2007-2009)]. Archivos de Prevención de Riesgos Laborales, 13, 135-140.

[8] Martínez-Jarreta, B., Gascón, S., Santed, M.A. and Goicoechea, J. (2007) Medical-legal analysis of aggression towards health professionals. An approach to a silent reality and its consequences on health [Análisis médicolegal de las agresiones a profesionales sanitarios. Aproximación a una realidad silenciosa y a sus consecuencias para la salud]. Medicina Clínica, 128, 307-310. doi:10.1157/13099583

[9] Martínez-León, M., Queipo-Burón, D., Irurtia-Muñiz, M.J. and Martínez-León, C. (2012) Análisis médico-legal de las agresiones a los profesionales sanitarios en Castilla y León (España) [Medico-legal analysis of the assaults on healthcare workers in Castilla y León (Spain)]. Revista Española de Medicina Legal, 38, 5-10. doi:10.1016/j.reml.2011.10.001

[10] Roldán, G.M., Garrido, L., Salazar, I.C. and Ramos, J.M. (2012) The violence suffered by healthcare professionals of the emergency services [La violencia sufrida por los profesionales sanitarios de los servicios de urgencias]. Unpublished document.

[11] Gerberich, S.G., Church, T.R., McGovern, P.M., Hansen, H.E., Nachreiner, N.M., Geisser, M.S., Ryan, A.D., Mongin, S.J. and Watt, G.D. (2004) An epidemiological study of the magnitude and consequences of work related violence: The Minnesota nurses' study. Occupational and Environmental Medicine, 61, 495-503. doi: 10.1136/oem.2003.007294 
[12] Maslach, C. and Jackson, S.E. (1982) Burnout in health professions: A social psychological analysis. In: Sanders, G.S. and Suls, J., Eds., Social Psychology of Health and Illness, Erlbanm, Hillsdale, 227-251.

[13] Sabbah, I., Sabbah, H., Sabbah, S., Akoum, H. and Droubi, N. (2012) Burnout among Lebanese nurses: Psychometric properties of the Maslach Burnout Inventory-Human Services Survey (MBI-HSS). Health, 4, 644-652. doi:10.4236/health.2012.49101

[14] Roldán, G.M., Salazar, I.C., Garrido, L. and Ramos, J.M. (2012) Psychological problems and burnout in healthcare professionals of the emergency services [Problemas psi- cológicos y desgaste profesional en los profesionales sanitarios de los servicios de urgencias]. Unpublished document.

[15] Mandiracioglu, A. and Cam, O. (2006) Violence exposure and burn-out among Turkish nursing home staff. Occupational Medicine, 56, 501-503. doi:10.1093/occmed $/ \mathrm{kql} 073$

[16] Whittington, R. (2002) Attitudes toward patient aggression amongst mental health nurses in the "zero tolerance" era: Associations with burnout and length of experience. Journal of Clinical Nursing, 11, 819-825. doi:10.1046/j.1365-2702.2002.00659.x 